\title{
Bipolar Plasmakinetic Vaporization versus the Standard Monopolar Transurethral Resection of the Prostate for Management of Benign Prostate Hyperplasia: Long Term Follow-Up of a Randomized Controlled Study
}

\author{
Essam Shalaby ${ }^{1 *}$, Osman Abd Elkader', Ammar Ghobish', and Ahmed Sakr ${ }^{2}$ \\ 'Department of Urology, Suez Canal University Hospital, Ismailia, Egypt, \\ ${ }^{2}$ Department of Urology, Zagazig University Hospital, Zagazig, Egypt
}

\begin{abstract}
Background: Monopolar Transurethral resection of the prostate (TURP) has dominated the surgical treatment of lower urinary tract symptoms (LUTS) due to BPH with relatively high TUR associated morbidity. Due to advanced technology, spurred the development of new surgical alternatives as plasmakinetic vaporization of the prostate to overcome the TURP related morbidity. Aim: To compare the outcomes of bipolar plasmakinetic vaporization of the prostate (PKVP) in saline with the standard monopolar TURP in-patients with bothersome LUTS. Patients and Methods: Two hundred and six patients with bothering LUTS were randomly divided into two groups, PKVP (GI) or TURP (GII). Patients demographics and preoperative data were compared, including prostate volume, international prostate symptoms score (IPSS), quality of life (QOL), maximum flow rate (Qmax), post voiding residual volume (PVR), prostate-specific antigen (PSA). Postoperative adverse events and long-term reoperation rates were also compared. Results: Preoperatively, both groups were comparable in demographic data, prostate volume, IPSS, Qmax, and PVR. Both groups showed comparative functional improvement in IPSS, QOL, Qmax, and PVR. Compared to GII patients, Gl patients had a significantly lower operative time ( $62.3 \pm 17 \mathrm{vs} .68 .6 \pm 20 \mathrm{~min}, p=0.03)$,

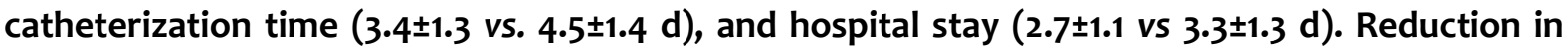
hemoglobin and serum sodium was significantly higher in GII patients. Clot retention occurs in $3.4 \%$ in G1 vs. $7.7 \%$ in G2 while blood transfusion needed for $8.9 \%$ of patients in Gll. After a 36-month follow-up, $10.5 \%$ and $7.7 \%$ of patients needed reoperation in GI and GII, respectively ( $p>0.05$ ). Conclusion: Long-term results revealed comparable safety and efficacy of PKVP and monopolar TURP in the management of bothersome LUTS secondary to BPH. However, PKVP seems to have lower perioperative morbidity (i.e. reduced blood loss, shorter catheterization time, shorter hospital stay, comparable reoperation rate, and better alternative to monopolar TURP.
\end{abstract}

Key words: Prostate, Plasmakinetic, vaporization, transurethral, resection

\section{Introduction}

For many decades, transurethral resection of the prostate (TURP) is considered the gold standard management of symptomatic benign prostatic hyperplasia $(\mathrm{BPH})^{(1)}$, with favorable long-term clinical outcomes $^{(2)}$. However, it is not without

"Corresponding Author: essamshalby1@hotmail.com 
shortcomings with high risk of perioperative adverse events and morbidity(3). Transurethral resection syndrome (TUR) is considered a significant risk post-TURP due to absorption of solute-free irrigation fluids, in addition to possibility of blood loss necessitating blood transfusion(4). Furthermore, prolonged hospitalization and longterm reoperation rates, especially after operating for large glands, would increase the cost of the procedure. Therefore, an alternative surgical procedure was looked for with comparable functional outcomes to TURP and decreased morbidity and lower cost ${ }^{(5)}$. TUR syndrome also was significantly considered with trying to replace the electrolyte-free irrigant (amino acetic acid) with an iso-osmolar physiological one with high degree of translucency and nonconductor medium to avoid interference with diathermia. Sterile water used previously as irrigation fluid but was associated with lethal hemolytic and hemodynamic effect(5). Plasmakinetic technology converted vaporized saline into gas around the resectoscope loop, then converting the gas to plasma, the excited sodium ions of the plasma give this technology the characteristic orange glow, and the highly ionized particles disrupt the organic molecular bonds. Consequently, enable rapid tissue vaporization or resection, depending on the use of new loop made of platinumiridium, that's able to withstand the electrical and thermal stresses ${ }^{(6)}$. PKVP eliminating the risk of TUR syndrome and carrying the hope to manage bladder outlet obstruction due to BPH with minimal side effects( $(7)$. The recent review of minimally invasive treatment option for lower urinary tract symptoms (LUTS) secondary to BPH recommended further well-designed studies to evaluate and validate their role of plasmakinetic technology in clinical practice ${ }^{(8)}$. Therefore, the current study aimed to compare the clinical efficacy and safety of bipolar plasmakinetic vaporization of the prostate (PKVP) in saline with the standard mono-polar TURP for symptomatic BPH.

\section{Patients and Methods}

\section{Ethical Standards}

All procedures performed in studies involving human participants were in accordance with the ethical standards of the institutional and/or national research committee and with the code of ethics of the World Medical Association Declaration of Helsinki (1964) and its later amendments. The study approved by institutional ethical committee no (3791) with an informed consent was obtained from all patients who wished to participate in the study. This article does not contain any studies with human participants or animals performed by any of the authors

\section{Study Design:}

Patients with bothersome LUTS secondary to $\mathrm{BPH}$ with prostatic volume of $40-80 \mathrm{cc}$ measured by transabdominal with/without transrectal ultrasound (TRUS); who had failed medical treatment with $\alpha$-adrenergic blockers \pm 5a-reductase inhibitors, also patients who met the other indication for endoscopic prostatectomy were included in the study. The study was carried in 3-urology institutes; Zagazig university hospital, Suez Canal university hospital, Ismailia oncology hospital. In each center, Patients were randomized into two groups and prospectively evaluated between Jun 2009 and March 2019. The study was conducted in accordance with the code of ethics of the World Medical Association Declaration of Helsinki and the study approved by institutional ethical committee (3791) and an informed consent was obtained from all patients who wished to participate in the study. Patients with associated bladder pathology were excluded from the study: including bladder mass or large bladder 
stones, chronic cystitis, or neurogenic bladder dysfunction, patients with previous prostatic surgery, prostate cancer and urethral surgery were also excluded. Demographic and perioperative parameters were recorded, including operative time, hemoglobin, hematocrit and sodium deficit, catheterization time, and length of hospital stay, the need for blood transfusion or clot retention. In addition, early adverse events and long-term complications were recorded. Baseline and follow-up data were compared both subjectively and objectively in terms of the international prostate symptoms score (IPSS), quality of life (QoL), peak flow rate (Qmax) (mL/sec), post-void residual urine volume (PVR) $(\mathrm{mL})$ and prostatic specific antigen (PSA). Postoperative follow-up was performed at one, 6 , and 12 months and then annually Figure (1).

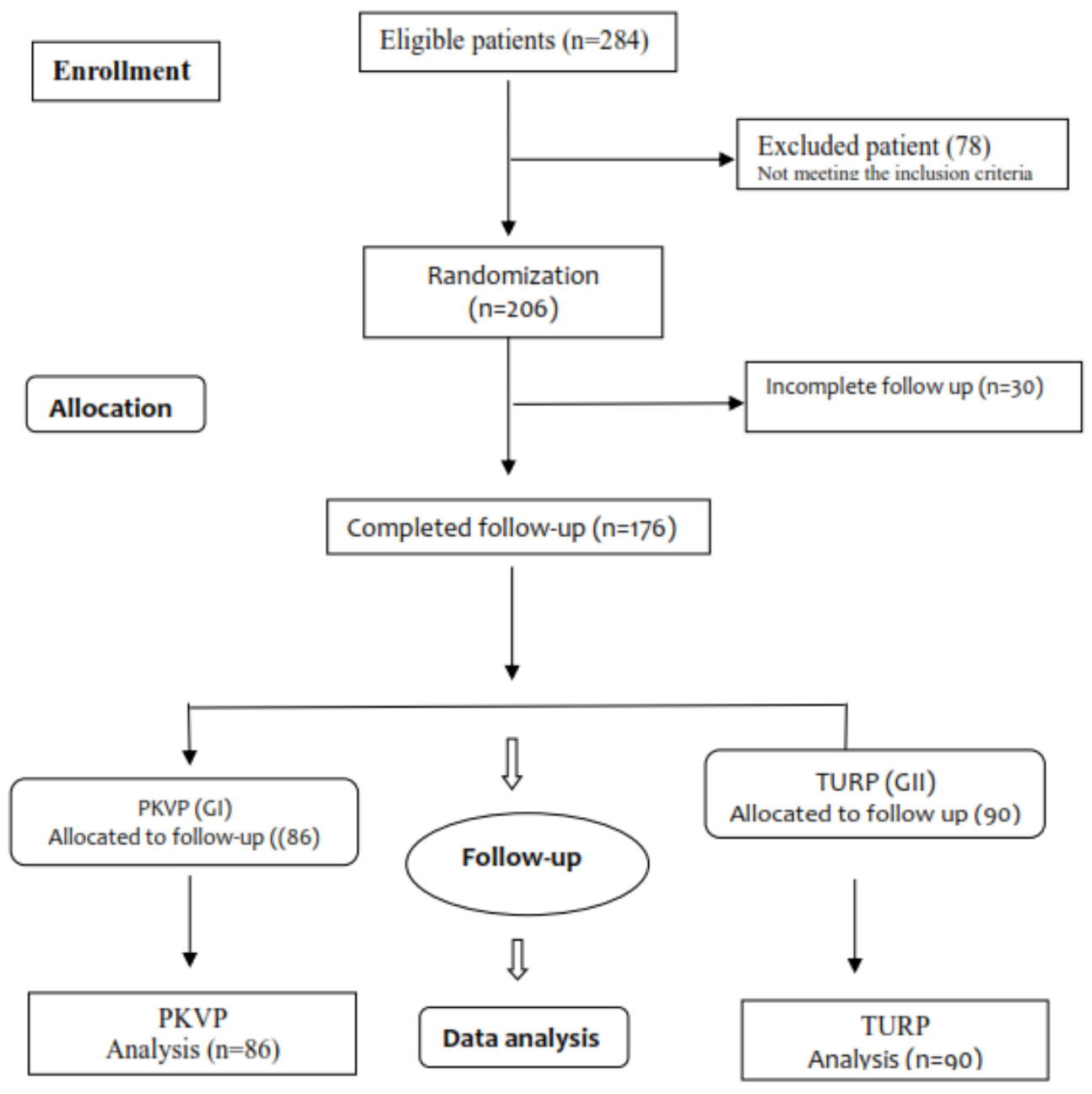

Figure 1: flowchart of study groups

Surgical Procedure:

Both endoscopic procedures were performed by expert surgeons in TUR of the prostate for more than 10 years, under spinal anesthesia and prophylactic antibiotics.
All patients underwent diagnostic cystoscopy to exclude other pathology, followed by urethral meatus calibration was performed using the Van Buren sounds up to 
$30 \mathrm{Fr}$. In-group (GI) isotonic saline $0.9 \%$ solution was used for PKVP and PKVP was performed using the plasmakinetic tissue management system with a bipolar electrosurgical device used endoscopically to instantly remove the obstructing prostate tissue by vaporization with saline irrigation(9-13). Prostatic vaporization by using PKVP device for systematically vaporize the prostatic tissue, maintaining gentle movement of the loop with the prostatic tissue until vaporization occurs by keeping the anatomical landmarks in consideration as in conventional TURP, and complete the intervention using the bipolar small loop to resect the apex of the prostate. Hemostasis was done, and 22 French three ways urethral catheter was inserted with continuous irrigation with normal saline until urine become clear and the catheter was removed after $24 \mathrm{~h}$ of clear urine. In-group (GII), the prostate was resected with standard manner from the bladder neck to verumontanum out to the prostatic capsule, after complete hemostasis was done 22 French three ways urethral catheter was inserted with continuous irrigation with normal saline until urine become clear and the catheter was removed after $24 \mathrm{~h}$ of clear urine.

\section{Statistical Analyses}

Descriptive data were presented in terms of number and percentages or medians (range)/means (SD) for categorical and continuous variables, respectively. Baseline and follow-up data were compared using the paired $t$-test. Fisher exact test and the Mann Whitney-U test were used to respectively compare categorical and continuous variables. A critical two-sided $p$-value $<0.05$ used for statistically significant differences. The sample size was calculated based on a $20 \%$ difference in change of IPSS level of $\leq 3$ points as the minimum clinically significant difference between both groups. Type I and II alpha errors $<5 \%$ and $<10 \%$ were considered, respectively, with a possible $20 \%$ drop out. Therefore, a sample size of 172 patients was estimated (86 in each group). Data was analyzed using the Statistical Package for Social Sciences for windows, version 20 (IBM৫ SPSS, Armonk, New York, USA).

\section{Results}

A total of 176 patients completed the postoperative follow-up, including 86 patients in $\mathrm{Gl}$ and 90 patients in Gll with mean (SD) ages of 69.1 (8.5) and 69.2(8.5) years for patients in $\mathrm{Gl}$ and Gll, respectively. Both groups were comparable in baseline and demographic data (Table 1). The mean prostate volume was $57.2( \pm 11.9)$ and 57.1 ( \pm 12$)$ cc, respectively. Twenty-one patients presented with indwelling urethral catheter secondary to urine retention: including 10 (11.6\%) in $\mathrm{Gl}$ and 11 (12.2\%) in Gll. Patients in $\mathrm{Gl}$, undergoing PKVP, showed significantly better perioperative parameters, including operative time, post-operative hemoglobin and serum sodium deficits, length of hospital stays and catheterization time, time and volume of post-operative irrigation, blood transfusion, clot retention and volume of resected tissue. Postoperative hemoglobin significantly decreased in both groups but was more evident in Gll compared to the GI patients (1.4 vs. $0.8 \mathrm{~g}$, respectively), blood transfusion was $8.9 \%$ in Gll only. Similarly, reduction in serum sodium was observed in both group, which was more significant in GIl patients (1.9 vs. $0.7 \mathrm{mEq}$ ) without clinical manifestation required intervention (Tables 2). After a mean (range) follow-up of 36 (27-51) mos., all subjective and objective voiding parameters significantly improved in both groups, including IPSS, Qmax, QoL and PVR compared to baseline data, starting in the first month postoperatively ( $\mathrm{Ta}$ ble 3) (Fig 2-4). 


\begin{tabular}{|l|c|c|c|}
\hline \multicolumn{4}{|c|}{ Table 1: Baseline and Demographic Parameters of Both Groups } \\
\hline Parameters & $\begin{array}{c}\text { Group I } \\
\mathrm{n}=86 \\
\text { Mean }( \pm \mathrm{SD})\end{array}$ & $\begin{array}{c}\text { Group II } \\
\mathrm{n}=90 \\
\text { Mean }( \pm \mathrm{SD})\end{array}$ & p-value \\
\hline Age (years) & $69.1( \pm 8.5)$ & $69.2( \pm 8.5)$ & 0.93 \\
\hline Patients with retention [n (\%)] & $10(11.6 \%)$ & $11(12.2 \%)$ & 0.9 \\
\hline Prostate volume (gram) & $57.2( \pm 11.9)$ & $57.1( \pm 12)$ & 0.93 \\
\hline IPSS & $19( \pm 2.4)$ & $18.9( \pm 2.4)$ & 0.71 \\
\hline Q max (ml/sec) & $6( \pm 1.6)$ & $6.2( \pm 1.8)$ & 0.39 \\
\hline PVR Vol (ml) & $157.6( \pm 111.1)$ & $160.8( \pm 111.9)$ & 0.85 \\
\hline Preoperative Hemoglobin (g) & $13.5( \pm 1.3)$ & $13.4( \pm 1.3)$ & 0.92 \\
\hline Preoperative serum sodium(mEq) & $139( \pm 1.9)$ & $139.1( \pm 1.9)$ & 0.82 \\
\hline $\begin{array}{l}\text { IPSS: International prostatic symptom score; Qmax: Maximum flow rate; } \\
\text { PVR: Post voiding residual urine volume }\end{array}$ \\
\hline
\end{tabular}

At the most recent follow-up visits, both groups were comparable in terms of adverse events, including erectile and ejaculatory dysfunction and reoperation rates ( 9 vs. 7 patients in GI and GII, respectively).
Reoperation was needed for 9 patients in $\mathrm{Gl}$ due to persistent or recurrent obstructing prostatic adenoma in 4 patients treated by TURP, bladder neck contracture (BNC) in 2 patients managed by transurethral

\begin{tabular}{|l|c|c|c|}
\hline \multicolumn{4}{|c|}{ Table 2: Perioperative Data for Both Groups } \\
\hline Parameters & $\begin{array}{c}\text { Group I } \\
\text { N=86 } \\
\text { Mean ( } \pm \text { SD })\end{array}$ & $\begin{array}{c}\text { Group II } \\
\text { N=90 } \\
\text { Mean ( } \pm \text { SD) }\end{array}$ & p-value \\
\hline Operative time/min & $62.3(17)$ & $68.6(20)$ & 0.03 \\
\hline Resected tissue volume/gm & $5.28(1)$ & $37.4(11.2)$ & 0.001 \\
\hline Perioperative irrigation/ L & $11.4(4.6)$ & $18.3(10.6)$ & 0.000 \\
\hline Post-operative irrigation/ L & $4.8(1.6)$ & $8.5(2.7)$ & 0.003 \\
\hline Length of hospital stay/d & $2.7(1.1)$ & $3.3(1.3)$ & 0.001 \\
\hline Catheter time/d & $3.4(1.3)$ & $4.5(1.4)$ & 0.001 \\
\hline Blood transfusion [n (\%)] & $0(0 \%)$ & $8(8.9 \%)$ & 0.005 \\
\hline Postop hemoglobin/g & $12.7(1)$ & $11.9(0.8)$ & 0.001 \\
\hline Postop serum sodium & $138.3(1.8)$ & $137.2(1.4)$ & 0.001 \\
\hline Postop hemoglobin deficit/g & $0.8(0.2)$ & $1.4(0.6)$ & 0.0001 \\
\hline Postop serum sodium deficit & $0.7(0.8)$ & $1.9(1.2)$ & 0.0001 \\
\hline Clot retention [n (\%)] & $3(3.4 \%)$ & $7(7.7 \%)$ & 0.04 \\
\hline
\end{tabular}


incision of the prostate (TUIP), while 3 patients had urethral stricture managed by visual urethrotomy (VIU). Reoperation in GIl patients was needed for urethral stric ture in four patients, BNC in 2 patients and recurrent obstructing prostatic adenoma in one patient, who were managed by VIU, TUIP and TURP respectively.

\begin{tabular}{|l|l|l|l|l|}
\hline \multicolumn{5}{|c|}{ Table 3: Long-term (36-month) follow-up data for both groups } \\
\hline \multirow{2}{*}{ Parameters } & Group & $\begin{array}{l}\text { Preoperative } \\
\text { Mean (SD) }\end{array}$ & $\begin{array}{l}\text { Postoperative } \\
\text { Mean (SD) }\end{array}$ & p-value \\
& Gl & $19(2.4)$ & $6.1(1.3)$ & 0.000 \\
\multirow{2}{*}{ IPSS } & Gll & $18.9(2.4)$ & $8.5(5.3)$ & 0.000 \\
\hline \multirow{2}{*}{ QOL index } & Gl & $4.6(1.32)$ & $1.8(0.91)$ & 0.000 \\
& GII & $4.9(1.80)$ & $2.1(1.21)$ & 0.000 \\
\hline \multirow{2}{*}{ Qmax (ml/sec) } & Gl & $6(1.6)$ & $18.5(2.1)$ & 0.000 \\
& Gll & $6.1(1.7)$ & $17.8(1.7)$ & 0.000 \\
\hline \multirow{2}{*}{ PVR/ ml } & Gl & $157.6(111.1)$ & $25.1(10)$ & 0.000 \\
& Gll & $161.2(114)$ & $27.2(8.3)$ & 0.000 \\
\hline IPSS: International prostatic symptom score; Qmax: Maximum flow rate; \\
PVR: Post voiding residual urine volume \\
\hline \multicolumn{5}{|l}{} \\
\hline
\end{tabular}

\section{Discussion}

Monopolar TURP was almost always referred to as the "gold standard" management of infravesical obstruction secondary to $\mathrm{BPH}$ based on the test of time $(\sim 80$ years) but not on randomized controlled studies against a known standard. Despite the technical advances in the procedure and instrumentation, significant concerns regarding perioperative morbidity and mortality are still present(4). TURP does not fit all sizes, its durability is debatable with less tissue removed, increased incidence of secondary procedures from 12.3 to 14.7 at 5 and 8 years of follow up ${ }^{(11,12)}$.

\begin{tabular}{|l|c|c|c|}
\hline \multicolumn{4}{|c|}{$\begin{array}{c}\text { Table 4: Long-term adverse events between both groups } \\
\text { (at the most recent follow-up) }\end{array}$} \\
\hline Parameters & $\begin{array}{c}\mathrm{GI}(86) \\
\text { No (\%) }\end{array}$ & $\begin{array}{c}\text { GII (90) } \\
\text { No (\%) }\end{array}$ & p-value \\
\hline Erectile dysfunction & $30(35 \%)$ & $33(37 \%)$ & 0.8 \\
\hline Retrograde ejaculation & $56(65 \%)$ & $58(64 \%)$ & 0.93 \\
\hline Persistent/recurrent adenoma & $4(4.6 \%)$ & $1(1.1 \%)$ & 0.07 \\
\hline Urethral stricture & $3(3.5 \%)$ & $4(4.4 \%)$ & 0.031 \\
\hline Bladder neck contracture & $2(2.3 \%)$ & $2(2.2 \%)$ & 0.96 \\
\hline Reoperation rate & $9(10.5 \%)$ & $7(7.7 \%)$ & 0.53 \\
\hline Secondary TURP & $4(4.6 \%)$ & $1(1.1 \%)$ & 0.16 \\
\hline Secondary VIU & $3(3.5 \%)$ & $4(4.4 \%)$ & 0.75 \\
\hline Secondary TUIP & $2(2.3 \%)$ & $2(2.2 \%)$ & 0.96 \\
\hline $\begin{array}{l}\text { TURP: transurethral resection of the prostate; VIU: Visual internal urethrotomy; } \\
\text { TUIP: Transurethral incision of the prostate. }\end{array}$ \\
\hline
\end{tabular}

Bipolar PKVP seems to be a significant effective alternative to monopolar TURP(9). In the current study, both procedures were equally effective in the management of bladder outflow obstruction due to BPH as evidenced by the improvement in IPSS and 
objective voiding parameters during the follow-up visits. However, PKVP has the advantages of less perioperative bleeding and blood transfusion, which were better than previously reported ${ }^{(6,10,11)}$. Moreover, reduction in hemoglobin was better with the PKVP group, with lower clot retention attacks recorded after PKVP than TURP, which was consistent with that previously reported done by Kaya et al $2007^{(11)}$. Poulakis et al performed a meta-analysis of 20 randomized controlled trials comparing transurethral electro vaporization techniques with TURP, which were as effective as TURP at 1-year follow-up with significant reduction in adverse events, including transfusion rate and episodes of clot retention ${ }^{(14)}$. Patients undergoing PKVP ( $\left.\mathrm{Gl}\right)$ had a shorter catheterization period post operatively, which was comparable to Kaya and Starkman studies ${ }^{(11,13)}$, but more prolonged than others ${ }^{(14)}$. The re-operation rates in the present study were $10.5 \%$ and $7.7 \%$ in patients undergoing PKVP and TURP, these rates were almost similar to $12 \%$ and $6.6 \%$ for PKVP and TURP respectively in the kaya group ${ }^{(11)}$, but higher than the $4.6 \%$ and $6.3 \%$ reported in Akman group ${ }^{(9)}$, which may be due to its short follow-up after (12 months) in there study. Urethral stricture in our study was diagnosed in $3.5 \%$ of PKVP patients, which was in agreement with $4 \%$ reported with Kaya group ${ }^{(11)}$,and slightly higher than the $2.5 \%$ reported with Poulakis group $^{(14)}$. This difference may be due to the larger prostate volume of our patients compared to Poulakis group (57g Vs. 45g). Patients undergoing PKVP in our study have a significantly lower length of hospital than those undergoing TURP; comparable to that reported by Kaya group ${ }^{(11)}$ and longer than reported by others $(10,14,15)$. The prolonged catheterization time and hospital stay in our study may be due to our institutions polices that considered the difficulties in patient transportation in the wide area draining our academic center. Another concern in PKVP (GI) was the absence of early post-operative sever irritative symptoms. Muslumanoglu et al showed sever post-operative irritative symptoms in $12.2 \%$ in PKVP group and $4 \%$ of required catheterization ${ }^{(7)}$. The absence of these symptoms in our study may be secondary to meticulous vaporization, avoidance of over coagulation and charring that may induce severe local irritation, slower healing of the prostatic fossa and more tissue edema. In our study, the PKVP procedure proves itself as a better alternative option than monopolar TURP for the management of BPH in terms of bloodless field, as the equipment simultaneously vaporizes tissue and controls bleeding, and using normal saline as an irrigant allowed better vision and eliminates a risk of TURP syndrome, which was previously approved $(15,16,17)$. This would be of interest for certain patients who are at high risk of bleeding, such as those with hepatic dysfunction, bleeding disorders, and cardiac patients with pacemakers ${ }^{(17,18)}$. In addition, it seems that PKVP may have an easier learning curve than monopolar TURP(15,16). The incidence of erectile dysfunction in our study was $35 \%$ and retrograde ejaculation was 65 $\%$ in PKVP group, which were comparable with those undergoing TURP; $37 \%$ and $64 \%$, respectively. These figures look higher than the $18 \%$ incidence of erectile dysfunction in the previously reported studies $(9,16)$. The prolonged operative time and long follow up period in our study may significantly impact such findings. However, the underlying cause of erectile dysfunction after endoscopic management of BPH is still a matter of controversy, with $4-35 \%$ of patients were reported to be affected, especially old age and those with preoperative $\mathrm{ED}^{(20,22-24)}$. Without clear conclusion to the moment, cavernosal nerve damage, fibrosis and thrombosis of cavernosal 


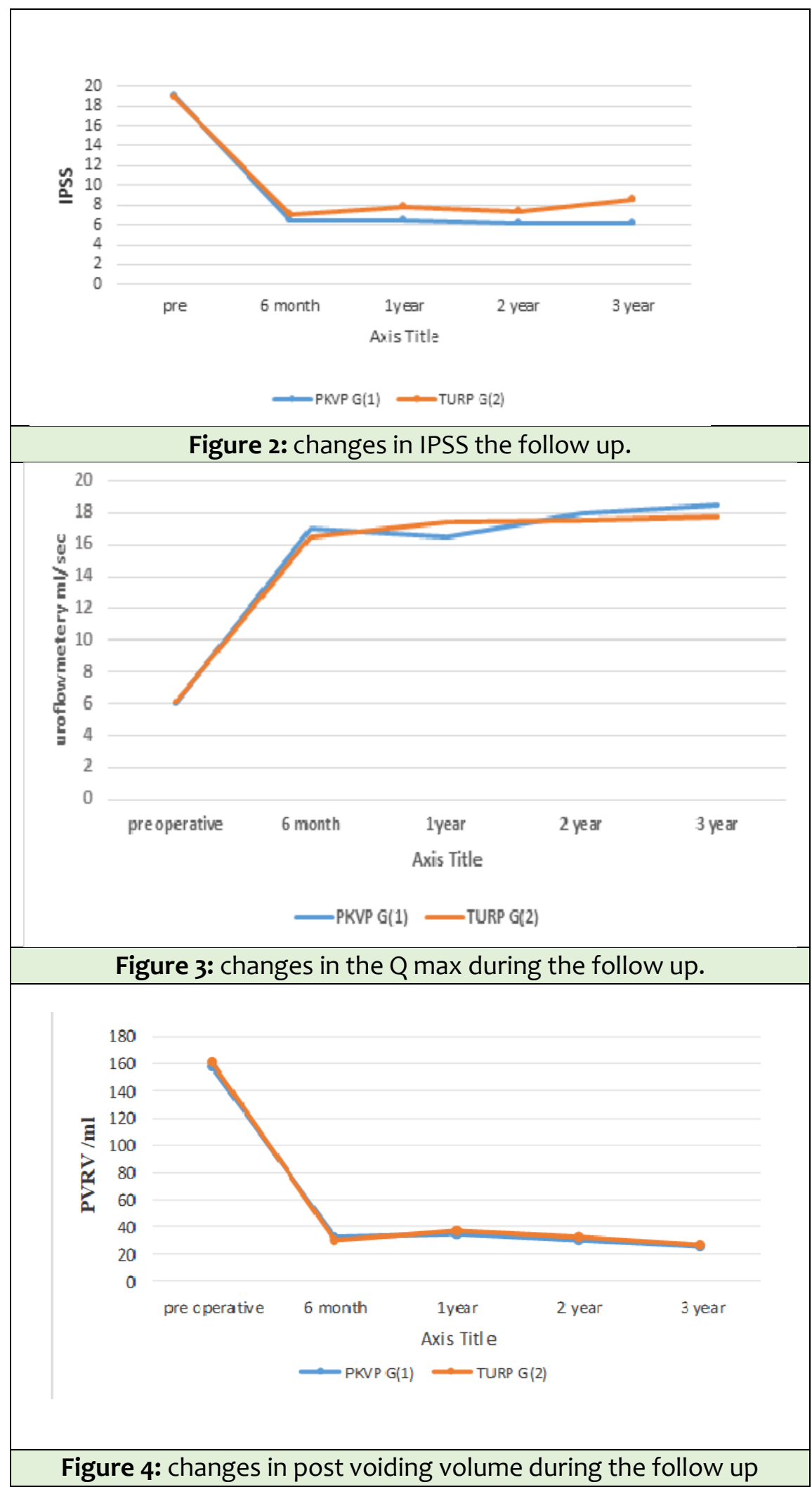

arteries and/or psychological troubles caused by ejaculatory failure or urethral sphincter dysfunction may be risk factors for this problem ${ }^{(22,24)}$. Histopathology of all patients undergoing TURP (GII) revealed no evidence of malignancy, while PKVP (GI) did not provide adequate tissue for histopathology, resulting in undiagnosed incidental prostate cancers, which sometimes may be of clinical significance. The present 
study is not without limitations, where it was not powered to detect the difference in the reoperation rates and the impact of each procedure on the sexual status was not detected using the available international questionnaire for erectile functions. A longer follow-up may enhance the reoperation rates between both procedures with survival evaluation of the time to the event. Although long-term results revealed comparable safety and efficacy of PKVP and monopolar TURP in the management of bothersome LUTS secondary to BPH. However, PKVP seems to have lower perioperative morbidity, including reduced blood loss and need for transfusion, absence of TUR syndrome, shorter catheterization time, shorter length of hospital stay, and comparable reoperation rates.

Funding Information: There is no funding agency.

Conflict of Interest: None declared.

\section{References}

1. Gratzke C, Bachmann A, Descazeaud A, et al (2015) EAU guidelines on the assessment of non-neurogenic male lower urinary tract symptoms including benign prostatic obstruction. Eur Urol; 67:1099-109.

2. Hsiang $\mathrm{Y}$, Pang $\mathrm{C}$, Hsing $\mathrm{T}$, et al (2018). Transurethral resection of prostate provides more favorable clinical outcomes compared with conservative medical treatment in-patient with urinary retention caused by BPO. BMC Geriatrics.Jan 16:18(1):15.

3. Sivaragan G, Borofsky MS, Shah O, et al (2015). The role of minimally invasive surgical techniques in the management of large-gland benign prostatic hypertrophy. Rev Urol; 17:140-9

4. Mebust WK, Holtgrewe HL, Cockett AT, et al (1989) Transurethral pros- tatectomy: immediate and postoperative complications. Cooperative study of 13 participating institutions evaluating 3,885 patients. J Urol, 41: 243-247.

5. Michielsen DP, Debacker T, De Boe $V$, et al. (2007) Bipolar transurethral resection in saline -an alternative surgical treatment for bladder outlet obstruction? J Urol Nov; 178(5):2035-9.

6. Issa MM. (2008) Technological advances in transurethral resection of the prostate: bipolar versus monopolar TURP. J Endourol ; 22:1587-95.

7. Muslumanoglu AY, Yuruk E, Binbay $M$, et al (2011) Transurethral resection of prostate with plasmakinetic energy;100 months results of prospective randomized trial. BJU Int.; 110: 546-549.

8. Chung ASJ, Woo HH (2018) Update on minimally invasive surgery and benign prostatic hyperplasia. Asian J Urol; 5: 22-27.

9. Akman T, Binbay M, Tekinarslan EM, et al (2012) Effects of bipolar and monopolar transurethral resection of the prostate on urinary and erectile function: a prospective randomized comparative study. BJU Int.; 111: 129-136

10. De Sio M, Autorino R, Quarto G, et al (2006). Gyrus bipolar versus standard monopolar transurethral resection of the prostate: a randomized prospective trial. Urology. Jan; 67(1):69-72.

11. Kaya C, Ilktac A, Gokmen E, et al (2007) The long-term results of transurethral vaporization of the prostate using plasmakinetic energy. BJU. Int. Apr; 99(4):845-8.

12. Bieri S, Iselin CE, Rohner S (1997) Capsular perforation localization and adenoma size as prognosis indicator of erectile dysfunctional after transurethral prostatectomy. Scand J Urol Nephrol; 31:545-548.

13. Starkman SJ, Santucci RA (2005) Comparison of bipolar transurethral 
resection of the prostate with standard transurethral prostatectomy: shorter stay, earlier catheter removal and fewer complications. BJU Int. Jan; 95(1):69-71.

14. Poulakis, V, Dahm, P, Witzsch,U., et al (2004) Transurethral electrovaporization Vs transurethral resection for symptomatic prostatic obstruction: a meta-analysis. BJU Int. Jul; 94(1):89-95.

15. Koca O, Oguz MK, Kaya C, et al (2014) Plasmakinetic vaporization versus transurethral resection of the prostate: six-year results. Turkish J Urol; 40 (3): 134-7.

16. Dunsmuir WD, Mcfarlane JP, Tan A, et al (2003) Gyrus bipolar electro vaporization vs transurethral resection of the prostate: a randomized prospective single-blind trial with $1 \mathrm{y}$ follow-up. Prostate Cancer Prostatic Dis; 6(2):182-6.

17. Tefekli A, Muslumanoglu AY, Boykal $M$, et al (2005) A hybrid technique using bipolar energy in transurethral prostate surgery: a prospective, randomized comparison. J Urol; 147:1339-43.

18. Madersbacher S, Lackner J, Brossner $C$ et al (2005) Reoperation, myocardial infarction and mortality after transurethral and open prostatectomy: a nation-wide, long-term analysis of 23123 cases. Eur Urol;47: 499-504.

19. Viorel Bucuras and Razvan Bardan (2011) Bipolar vaporization of the prostate: is it ready for the primetime? Ther Adv Urol. Dec; 3(6): 257261.

20. Lindner A, Golomb J, Korczak D, et al (1991) Effects of prostatectomy on sexual function. Urology; 38: 2628.

21. Pereira-Correia JA, Danilson KMS, Santos JBP, et al (2012) Green light HPStm 120-W Laser Vaporization of the prostate $(>60 \mathrm{ml})$ : A 2-year randomized double- blind prospective urodynamic investigation. BJU Int; 110: 1184-1189.

22. Soderdahl D, Knight R, Hansberry $K$ (1996) Erectile dysfunction following transurethral resection of the prostate. J Urology; 156: 1354-1356.

23. Tscell R, Largo M, Poppinghaus E, et al (1995). Incidence of erectile impotence secondary to transurethral resection of benign prostatic hyperplasia, assessed by preoperative and postoperative Snape Gauge tests. J Urol; 153: 1491-1493.

24. Gu RZ, Xia SJ (2011) surgical options for benign prostatic hyperplasia: impact on sexual function and risk factors. Natl J Androl; 17:837-41. 